\title{
Ambulatory Surgical Center
}

National Cancer Institute

\section{Source}

National Cancer Institute. Ambulatory Surgical Center. NCI Thesaurus. Code C51957.

A facility which primary purpose is to provide elective surgical care, in which the patient is admitted to and discharged from within the same working day and is not permitted to stay overnight, and which is not part of a hospital. An office maintained by a physician for the practice of medicine, or dentistry shall not be construed to be an ambulatory surgical center. 